\title{
Anti-Inflammatory Cytokine Interleukin-4 Inhibits Inducible Nitric Oxide Synthase Gene Expression in the Mouse Macrophage Cell Line RAW264.7 through the Repression of Octamer-Dependent Transcription
}

\author{
Miki Hiroi, Yoshiichi Sakaeda, Hana Yamaguchi, and Yoshihiro Ohmori \\ Division of Microbiology and Immunology, Department of Oral Biology and Tissue Engineering, \\ Meikai University School of Dentistry, 1-1 Keyakidai, Sakado 350-0283, Saitama, Japan \\ Correspondence should be addressed to Yoshihiro Ohmori; ohmori@dent.meikai.ac.jp
}

Received 31 October 2013; Revised 30 November 2013; Accepted 2 December 2013

Academic Editor: Elisabetta Buommino

Copyright (C) 2013 Miki Hiroi et al. This is an open access article distributed under the Creative Commons Attribution License, which permits unrestricted use, distribution, and reproduction in any medium, provided the original work is properly cited.

\begin{abstract}
Inducible nitric oxide synthase (iNOS) is a signature molecule involved in the classical activation of M1 macrophages and is induced by the Nos 2 gene upon stimulation with Thl-cell derived interferon-gamma (IFN $\gamma$ ) and bacterial lipopolysaccharide (LPS). Although the anti-inflammatory cytokine IL-4 is known to inhibit Nos 2 gene expression, the molecular mechanism involved in the negative regulation of Nos 2 by IL- 4 remains to be fully elucidated. In the present study, we investigated the mechanism of IL-4mediated Nos 2 transcriptional repression in the mouse macrophage-like cell line RAW264.7. Signal transducer and activator of transcription 6 (Stat6) knockdown by siRNA abolished the IL-4-mediated inhibition of Nos 2 induced by IFN $\gamma / \mathrm{LPS}$. Transient transfection of a luciferase reporter gene containing the $5^{\prime}$-flanking region of the Nos 2 gene demonstrated that an octamer transcription factor (OCT) binding site in the promoter region is required for both positive regulation by IFN $\gamma / \mathrm{LPS}$ and negative regulation by IL-4. Although IL-4 had no inhibitory effect on the DNA-binding activity of constitutively expressed Oct-1, IL4 -induced Nos2-reporter transcriptional repression was partially attenuated by overexpression of the coactivator CREB-binding protein (CBP). These results suggest that a coactivator/cofactor that functionally interacts with Oct-1 is a molecular target for the IL-4-mediated inhibition of Nos2 and that IL-4-activated Stat6 represses Oct-1-dependent transcription by competing with this coactivator/cofactor.
\end{abstract}

\section{Introduction}

Macrophages function in various aspects of the inflammatory reaction, innate and acquired immunity, and tissue remodeling, and the functional competence of macrophages are generally acquired in response to a diverse array of stimuli encountered in the tissue microenvironment [1]. Bacterial cellular components, such as lipopolysaccharide (LPS) and type I helper T cell (Th1)-derived cytokine interferongamma (IFN $\gamma)$, are well-known macrophage-activating stimuli that promote antimicrobial and antitumor functions [13]. These so-called classically activated macrophages, or M1 macrophages, produce large amounts of proinflammatory cytokines, reactive oxygen intermediates, and such reactive nitrogen intermediates as nitric oxide (NO), which is generated by inducible NO synthase (iNOS) encoded by the Nos2 gene $[4,5]$. In contrast, the Th2-derived cytokines interleukin-4 (IL-4) and IL-13 induce an alternative mode of macrophage activation, resulting in macrophages that participate in scavenging, the anti-inflammatory response, wound healing, and tissue remodeling by enhancing the expression of the mannose receptor, the IL-1 receptor antagonist, and arginase I [3, 6-8]. These Th2-derived cytokines also inhibit the expression of proinflammatory genes, including Nos2, in classically activated macrophages [9-12], thereby further promoting the polarization toward the type II response.

The intracellular signaling pathway for IL-4 is, at least in part, mediated by signal transducer and activation of 
transcription 6 (Stat6), a latent cytoplasmic transcription factor that is phosphorylated at a tyrosine residue (Tyr641) by Janus kinase 1 (Jak1) after IL-4 binds to the IL- 4 receptor $[13,14]$. Phosphorylated Stat6 assembles in a dimeric form, translocates to the nucleus, binds to a specific cis-regulatory sequence, and mediates the transcriptional activation of IL4-inducible genes [13-18]. IL-4-induced Stat6 also functions as a negative regulator of the IFN $\gamma$-induced Statl-dependent transcriptional activation of macrophage genes, and previous studies have shown that Stat6 directly and/or indirectly suppresses IFN $\gamma$-induced Statl-dependent transcription [19-22]. Although IL-4-activated Stat6 appears to be indispensable for the negative regulation of IL- 4 [17, 19], the molecular mechanisms by which IL-4-activated Stat6 inhibits the macrophage gene expression induced by LPS and IFN $\gamma$ remain to be fully clarified.

Transcriptional regulation of the mouse Nos2 gene induced by LPS and IFN $\gamma$ in macrophages has been extensively studied [23-30]. The $5^{\prime}$-proximal region of the Nos 2 gene (region I) contains a TATA box and binding motifs for octamer transcription factor (OCT) and nuclear factor $\kappa \mathrm{B}(\mathrm{NF}-\kappa \mathrm{B})$, which primarily mediate the transcriptional activation induced by LPS [23, 24, 31-33]. The distal regulatory region (region II) located $0.9 \mathrm{~kb}$ upstream from the transcription start site principally contains regulatory sequences for mediating IFN-induced activation. In this region, IFN-stimulated response elements (ISREs) and the IFN $\gamma$-activation sequence (GAS) have been identified as binding sties for members of the IFN regulatory factor (IRF) family, IFN-stimulated gene factor 3 (ISGF3 composed of Stat1, Stat2, and IRF-9), and Stat1 [25-28, 30], which mediate responsiveness to IFNs. The transcriptional synergy of the Nos 2 gene induced by IFN $\gamma$ and LPS has been suggested to be mediated by a functional cooperation between LPSactivated transcription factors, such as $\mathrm{NF}-\kappa \mathrm{B}$, at region I and IFN-induced transcription factors at region II [23, $26,30]$. IL-4 also negatively regulates the expression of the Nos 2 gene, particularly the IFN $\gamma$-induced expression of Nos 2 in mouse macrophages [12]. The mechanisms involved in the IL-4-mediated inhibition of Nos2 have been shown to depend upon the negative regulation of IFN $\gamma$-induced IRF-1 through the inhibition of IRF-1 expression [34, 35], through competition for IRF-1 binding with IL-4-induced IRF-2 [36], or through an attenuation of the interaction with IFN consensus sequence-binding protein (ICSBP, known as IRF-8) [28]. Although the mechanisms involved in the IFN $\gamma$ induced expression of the Nos 2 gene by IL- 4 have focused on the negative regulation of IRF-1, the mechanism of the IL-4mediated inhibition of the Nos 2 gene induced by IFN $\gamma$ and LPS remains to be fully elucidated.

In the present study, we analyzed the molecular mechanisms by which IL- 4 inhibits the transcriptional activation of the mouse Nos 2 gene upon stimulation with IFN $\gamma$ and LPS in the mouse macrophage cell line RAW264.7. We demonstrated that Stat 6 knockdown by siRNA abolishes the IL-4-mediated inhibition of Nos 2 mRNA expression. Using the transient transfection of a luciferase reporter gene containing the $5^{\prime}$ regulatory region of the Nos 2 gene, we identified the OCT site in the proximal promoter region of the Nos 2 gene as the responsive region for IL-4-mediated repression. These data indicate that IL-4-activated Stat6 inhibits the OCTdependent transcriptional activation of the Nos 2 gene in RAW264.7 cells.

\section{Materials and Methods}

2.1. Reagents. LPS prepared using Westphal phenolic extraction from Escherichia coli (0111:B4) was obtained from SigmaAldrich Corporation (St. Louis, MO, USA). Recombinant mouse IFN $\gamma$ and IL- 4 were obtained from Chemicon International (Temecula, CA, USA) and R\&D Systems (McKinley Place, NE, USA), respectively. Rabbit polyclonal antibodies against Stat6 (sc-981), $\beta$-actin (sc-1616), Bob-1/BOB.1 (sc955), TATA-binding protein (TBP; sc-204), Oct-1 (sc-232), and Oct-2 (sc-233) were obtained from Santa Cruz Biotechnology (Hercules, CA, USA).

2.2. Cell Culture. The mouse macrophage-like cell line RAW264.7 was obtained from American Type Culture Correction (Manassas, VA, USA) and cultured in Dulbecco's Modified Eagle's Medium (DMEM; Invitrogen, Grand Island, NY, USA) supplemented with $10 \%$ fetal bovine serum (FBS; Bio West, Miami, FL,USA) and $1 \%$ penicillin G/streptomycin sulfate (Invitrogen). For all experiments, the cells were subcultured until a 70\% 80\% confluent monolayer was achieved. The cells were then pretreated with $10 \mathrm{ng} / \mathrm{mL}$ recombinant mouse IL- 4 for $30 \mathrm{~min}$ prior to stimulation with $10 \mathrm{ng} / \mathrm{mL}$ mouse IFN $\gamma$ and/or $100 \mathrm{ng} / \mathrm{mL}$ LPS for the indicated time. The mouse B cell leukemia cell line BCL1-B20 (RCB2618) [37] was obtained from the RIKEN Bioresource Center (Tokyo, Japan) and cultured in RPMI1640 supplemented with 10\% FBS and $1 \%$ penicillin G/streptomycin sulfate.

2.3. Determination of $\mathrm{NO}_{2}{ }^{-}$Accumulation. Nitrite accumulation in the culture supernatant was measured by the Griess assay, as described previously [38]. Briefly, 100- $\mu \mathrm{L}$ aliquots of culture supernatant were incubated with an equal volume of Griess reagent [1\% sulfanilamide/0.1\% N-(1naphthyl) ethylenediamine dihydrochloride $\left./ 2.5 \% \mathrm{H}_{3} \mathrm{PO}_{4}\right]$ at room temperature for $10 \mathrm{~min}$. The absorbance of the samples at $550 \mathrm{~nm}$ was measured using a microplate reader (Thermo Fisher Scientific, Waltham, MA, USA), and the $\mathrm{NO}_{2}{ }^{-}$content was determined using sodium nitrite as a standard. The cellular protein in each culture well was also determined by the Bradford method [39]. NO production was expressed as nmol per protein content.

2.4. Preparation of Total RNA and Northern Hybridization Analysis. The preparation of total RNA by the guanidine isothiocyanate-cesium chloride method and northern hybridization analysis were performed as previously described [40]. In some experiments, total RNA was prepared using the Fast Pure RNA kit (Takara, Otsu, Japan). The cDNA probes for mouse inducible nitric oxide synthase (Nos2) and rat glyceraldehyde-3-phosphate dehydrogenase (Gapdh) were described elsewhere $[40,41]$. 
2.5. Quantitative Real-Time RT-PCR. cDNA was synthesized from the purified total RNA using a high-capacity cDNA reverse transcription kit (Life Technologies, Carlsbad, CA, USA) according to the manufacturer's instructions. Realtime PCR probes and primers specific for mouse Nos2, Stat6, Oct-1, and Oct-2, as shown in Table 1 in the Supplementary Material available at http://dx.doi.org/10.1155/2013/369693, were selected using the Universal Probe Library Assay Design Center (Roche Applied Science, Basel, Switzerland). Aliquots of cDNA were amplified using a LightCycler 480 Real-Time PCR System (Roche) and TaqMan Gene Expression Master Mix (Life Technologies) according to the manufacturer's instructions. The PCR cycling conditions were as follows: $95^{\circ} \mathrm{C}$ for $5 \mathrm{~min}$ and 40 cycles of $95^{\circ} \mathrm{C}$ for $10 \mathrm{~s}, 60^{\circ} \mathrm{C}$ for $30 \mathrm{~s}$, and $72^{\circ} \mathrm{C}$ for $10 \mathrm{~s}$. The transcript levels were calculated relative to the $18 \mathrm{~S}$ rRNA levels as an internal control.

2.6. siRNA-Mediated Knockdown. Cells were seeded in 24well plates and transfected with $100 \mathrm{nM}$ of SMART pool siRNA targeting mouse Stat6 (a mixture of the four different Stat6 on-target siRNA oligonucleotides: AGGCUUCACCAUCGAGUAA, CCAAGACAACAACGCCAAA, GGAUGAAGUCCUGCGAAC, and UGGUCAUCGUGCAUGGUAA) using the Dharmafect Duo transfection reagent according to the manufacturer's instructions (Thermo Scientific). The ON-TARGETplus nontargeting pool containing four different nontargeting siRNA oligonucleotides (Thermo Scientific) was used as a negative control. At 36 hours after siRNA transfection, the cells were pre-treated with IL-4 for $30 \mathrm{~min}$ and stimulated with IFN $\gamma$ and/or LPS for 8 hours before preparation of total RNA for real-time RT-PCR or total cellular lysate for western blotting.

2.7. Construction of the Luciferase Reporter Gene. The promoter/enhancer region of the mouse Nos2 gene (-996 +104 ; see [23]) was isolated from mouse genomic DNA (Promega, Madison, WI, USA) by PCR using Pfx Ultima DNA polymerase (Invitrogen). The PCR primers are listed in supplemental Table 2. The gene-specific forward and reverse primers contained restriction enzyme sites (MluI and BglII, resp.); the PCR product was digested with MluI and BglII, analyzed on a $1.0 \%$ agarose gel, and purified using a DNA extraction kit (Qiagen, Valencia, CA, USA) according to the manufacturer's instructions. The purified PCR product $(-996 \sim+104)$ was then subcloned into an MluI- and BglIIdigested pGL2 luciferase reporter plasmid (Promega), and the resulting plasmid was designated as pNOS-996. A series of deletion mutants of the $5^{\prime}$-flanking region of the Nos 2 gene was constructed by restriction enzyme digestion of pNOS-996 (SmaI for -772, SacI for -333, and PstI for -44). Another series of proximal $5^{\prime}$-flanking region of deletion mutants, corresponding to the region between +104 and -143 , $-86,-62$, or -17 , was generated by PCR using forward and reverse primers containing $M l u I$ and $B g l I I$ sites, respectively (supplemental Table 2). The PCR products were digested with MluI and BglII and subcloned into the pGL2 luciferase reporter plasmid.
Site-specific mutations of the proximal $\kappa \mathrm{B}$ site and the OCT site were created by a modification of the two-round PCR method [42]. In brief, the $\kappa \mathrm{B}$ site $\left(5^{\prime}\right.$-GGGACTCTCC$3^{\prime}$ ) was mutated to $5^{\prime}$-ccACatcgat-3, where the lowercase letters indicate the mutant sequences and the italics indicate the ClaI site, using two sets of PCR primers containing the mutant sequences (supplemental Table 2). The OCT site $\left(5^{\prime}-\right.$ ATGCAAAA $-3^{\prime}$ ) was mutated to $5^{\prime}-\operatorname{cgtacgAA}-3^{\prime}$, where the lowercase letters and italics indicate the mutant sequence and BsiWI site, respectively, using two sets of primers. The detailed methods for the construction of the mutant reporter constructs are described in supplemental Figure 1. The resulting mutant constructs were confirmed by sequencing.

2.8. Transient Transfection and Luciferase Reporter Assay. RAW264.7 cells were seeded into 24-well plates at a density of $1 \times 10^{4}$ cells/well in DMEM supplemented with $10 \%$ FBS and cultured for 16 hours prior to transfection. The cells were then transiently transfected with the luciferase reporter plasmids and the pRL-TK reference Renilla luciferase plasmid (Promega) using FuGene transfection reagents (Roche) according to the manufacturer's instructions. In some experiments, the CREB-binding protein (CBP) expression vector [43] (kindly proved by Dr. Christopher K. Glass, University of California San Diego) or a control vector (pCMV) was cotransfected with the luciferase reporter plasmid. After 24 hours, the cells were pre-treated with IL-4 for $30 \mathrm{~min}$ and stimulated with IFN $\gamma$ and/or LPS for 8 hours. The firefly and Renilla luciferase activities were assayed using reagents provided by Promega according to their instructions. For standardization of the transfection efficiency, the luciferase activity from Nos 2 was normalized to the Renilla luciferase activity.

2.9. Preparation of Cellular Extracts. Nuclear and cytosolic extracts were prepared using a modification of the method of Dignam et al. [44], as described previously [45]. After stimulation, the cells were washed with ice-cold PBS, harvested, and resuspended in $300 \mu \mathrm{L}$ of hypotonic buffer $\mathrm{A}$ (10 mM HEPES, pH 7.9, 10 mM KCl, 0.1 mM EDTA, $0.1 \mathrm{mM}$ EGTA, $1 \mathrm{mM}$ DTT, $1 \mathrm{mM}$ PMSF, and $10 \mu \mathrm{g} / \mathrm{mL}$ of leupeptin, antipain, aprotinin, and pepstatin) for $10 \mathrm{~min}$ on ice. The cells were lysed in $0.6 \%$ NP-40 by vortexing for 10 seconds. The nuclei were separated from the cytosol by centrifugation at $12,000 \times \mathrm{g}$ for 30 seconds, and the supernatant was saved as a cytosolic fraction. The residual nuclei were washed with $600 \mu \mathrm{L}$ of buffer A, resuspended in buffer C $(20 \mathrm{mM}$ HEPES, pH 7.9, 25\% glycerol, 0.4 M NaCl, 1 mM EDTA, $1 \mathrm{mM}$ EGTA, $1 \mathrm{mM}$ DTT, $1 \mathrm{mM}$ PMSF, and $10 \mu \mathrm{g} / \mathrm{mL}$ of leupeptin, antipain, aprotinin, and pepstatin), and briefly sonicated on ice. Nuclear extracts were obtained by centrifugation at $12,000 \times \mathrm{g}$ for $10 \mathrm{~min}$; the protein concentration was measured using the Bradford method [39] with a protein dye reagent (Bio-Rad, Hercules, CA, USA).

2.10. Electrophoretic Mobility Shift Assay (EMSA). The following oligonucleotides (sense strand) were used in the EMSA: 
wt NOS OCT [33]; 5'-tcgaCAGTTATGCAAAATAGCT$3^{\prime}$; mut NOS OCT, $5^{\prime}$-tacgaCAGTTCGTACGAATAGCT-3'; and wt Ig $\kappa$ B OCT [46], $5^{\prime}$-tcgaTAATAATTTGCATACCT- $3^{\prime}$. The underlined sequence and italics represent the consensus sequence for OCT and the mutant sequences, respectively. For the binding reactions, nuclear extracts ( $5 \mu \mathrm{g}$ protein) were incubated in $12.5 \mu \mathrm{L}$ (total volume) containing $20 \mathrm{mM}$ HEPES (pH 7.9), 50 mM KCl, 0.1 mM EDTA, 1 mM DTT, 5\% glycerol, $200 \mu \mathrm{g} / \mathrm{mL} \mathrm{BSA}$, and $1.25 \mu \mathrm{g}$ of poly(dI-dC) for 15 minutes at room temperature. $\left[{ }^{32} \mathrm{P}\right]$-Labeled oligonucleotide $\left(0.5 \mathrm{ng}, 5 \times 10^{5} \mathrm{cpm}\right)$ was then added to the reaction mixture and incubated for 15 minutes at room temperature. The reaction products were analyzed by electrophoresis through a $5 \%$ polyacrylamide gel with $0.25 \times$ TBE buffer $(22.3 \mathrm{mM}$ Tris, $22.2 \mathrm{mM}$ borate and $0.5 \mathrm{mM}$ EDTA). In some experiments, rabbit antibodies against Oct-1, Oct-2, and Bob-1/BOB.1 were added prior to electrophoresis. The dried gels were analyzed by autoradiography and phosphorescence detection.

2.11. Western Blotting Analysis. Cells were harvested after stimulation and resuspended in RIPA buffer [0.1\% SDS, $1 \%$ NP-40, $5 \mathrm{mM}$ EDTA, $0.5 \%$ sodium deoxycholate, $150 \mathrm{mM}$ $\mathrm{NaCl}, 50 \mathrm{mM}$ HEPES (pH 8.0), $2 \mu \mathrm{g} / \mathrm{mL}$ leupeptin, $20 \mathrm{mg} / \mathrm{mL}$ aprotinin, $20 \mu \mathrm{g} / \mathrm{mL} \mathrm{Na}_{3} \mathrm{VO}_{4}, 10 \mathrm{mM} \mathrm{NaF}, 1 \mathrm{mM} \mathrm{PMSF}$, and $2 \mathrm{mM} \mathrm{DTT}]$ and centrifuged at $4^{\circ} \mathrm{C}, 12,000 \times \mathrm{g}$ for $10 \mathrm{~min}$; the supernatant was recovered as the total cell lysate. In some experiments, nuclear extracts were used as the samples. The protein concentration was measured by the Bradford method [39] using a protein dye reagent (Bio-Rad). Equal amounts of protein were denatured in SDS sample buffer $[62.5 \mathrm{mM}$ Tris- $\mathrm{HCl}$ ( $\mathrm{pH} 6.8$ ) containing 2\% SDS, 20\% glycerol, 5\% 2mercaptoethanol, and $0.2 \%$ bromophenol blue], separated by SDS-polyacrylamide gel electrophoresis, and transferred to polyvinylidene fluoride (PVDF) membranes (Millipore, Bedford, MA, USA). The membranes were blocked with 5\% non-fat milk in TBS-T [ $50 \mathrm{mM}$ Tris- $\mathrm{HCl}$ ( $\mathrm{pH}$ 7.4) containing $150 \mathrm{mM} \mathrm{NaCl}$ and $0.1 \%$ Tween-20], incubated overnight with primary antibodies at $4^{\circ} \mathrm{C}$, and washed three times with TBST. The blots were then incubated for 1 hour at room temperature with secondary antibodies conjugated to horseradish peroxidase and washed again with TBS-T. The blots were developed using a SuperSignal West Pico chemiluminescence substrate kit (Pierce, Rockford, IL, USA).

2.12. Statistical Analysis. Student's $t$ tests for paired data were used to test for statistically significant differences with Prism 5 software (GraphPad Software, La Jolla, CA, USA). The results are expressed as the mean \pm SEM of at least three experiments. A $P$ value less than 0.05 was considered to be statistically significant.

\section{Results}

3.1. Inhibition of IFN $\gamma$ - and/or LPS-Induced Nos 2 mRNA Expression by IL-4 Depends on Stat 6 in RAW264.7 Cells. We initially assessed whether IL-4 inhibits the NO production induced by IFN $\gamma$ and/or LPS in the macrophage-like cell line RAW264.7 (Figure 1(a)). RAW264.7 cells were treated with

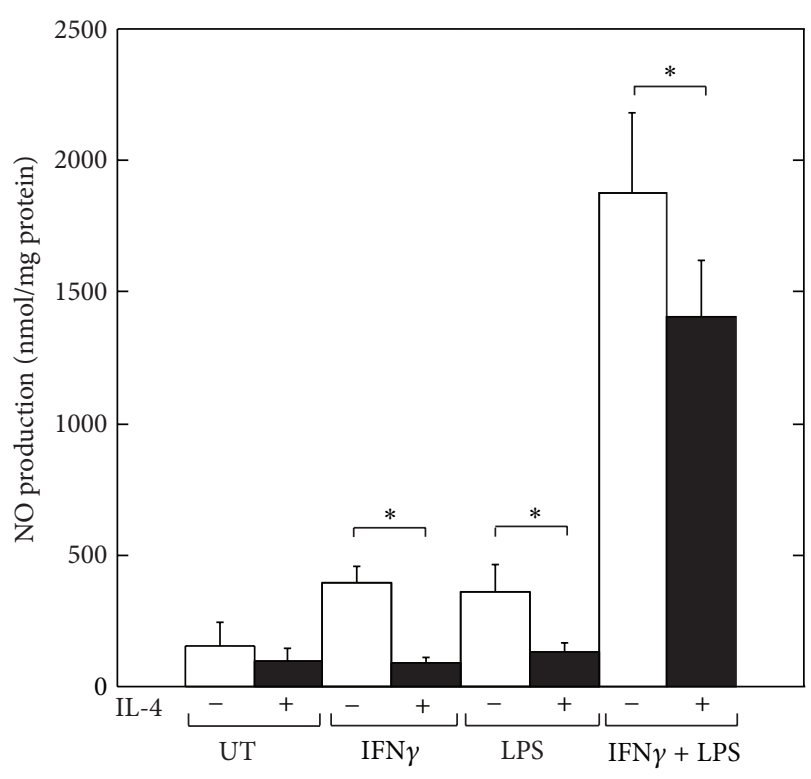

(a)

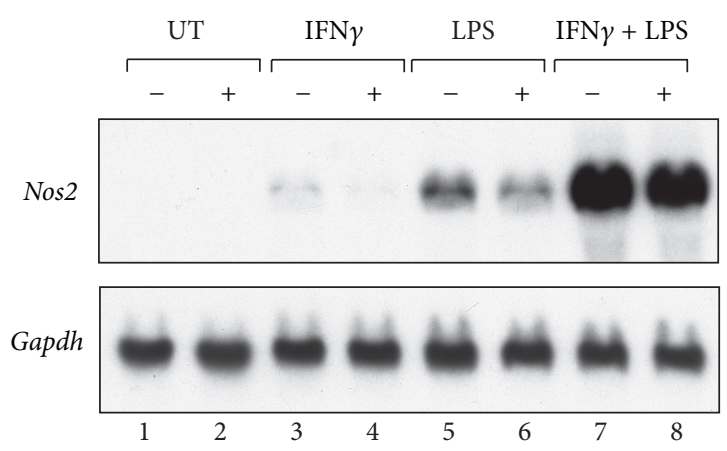

(b)

FIGURE 1: IL- 4 inhibits IFN $\gamma$ - and/or LPS-induced NO production and Nos 2 mRNA expression in RAW264.7 cells. (a) RAW264.7 cells were treated with medium alone (untreated, UT) or IL-4 $(10 \mathrm{ng} / \mathrm{mL}$ ) for $30 \mathrm{~min}$ prior to stimulation with $\operatorname{IFN} \gamma(10 \mathrm{ng} / \mathrm{mL})$ and/or LPS $(100 \mathrm{ng} / \mathrm{mL})$. The culture supernatants were harvested and assessed for NO production by the Griess assay. The protein concentrations of the residual cells in the cultures were also determined. Each column and bar represents the mean \pm SEM of three independent experiments. The asterisks denote a statistically significant difference compared to the cultures with IL- $4,\left({ }^{*} P<0.05\right.$; Student's $t$ test). (b) RAW264.7 cells were treated with medium alone or IL-4 $(10 \mathrm{ng} / \mathrm{mL})$ for $30 \mathrm{~min}$ prior to stimulation with IFN $\gamma(10 \mathrm{ng} / \mathrm{mL})$ and/or LPS $(100 \mathrm{ng} / \mathrm{mL})$ for 8 hours before the preparation of total RNA and analysis of the Nos $2 \mathrm{mRNA}$ level by northern hybridization. The data shown are representative of three independent experiments.

medium alone or IL- 4 for 30 min prior to stimulation with IFN $\gamma$ and/or LPS for 48 hours, and the culture supernatants were then harvested for the analysis of NO production. As shown in Figure 1(a), IL-4 significantly inhibited NO production in the RAW264.7 cells stimulated with IFN $\gamma$ and/or LPS. To examine the inhibitory effect of IL- 4 on IFN $\gamma$ and/or LPS-induced Nos 2 mRNA expression, the cells were pretreated with IL-4 for $30 \mathrm{~min}$ and stimulated with IFN $\gamma$ and/or LPS for 8 hours; total RNA was then prepared and 


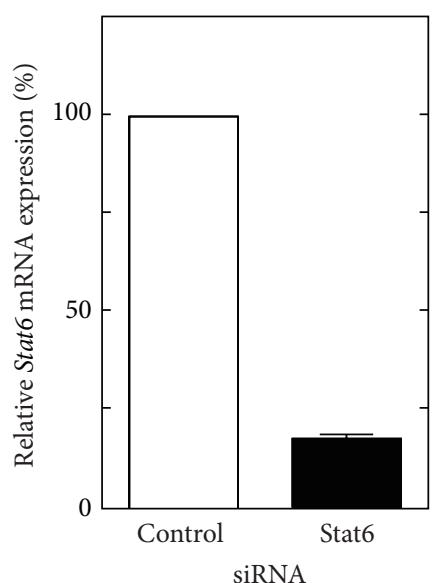

(a)

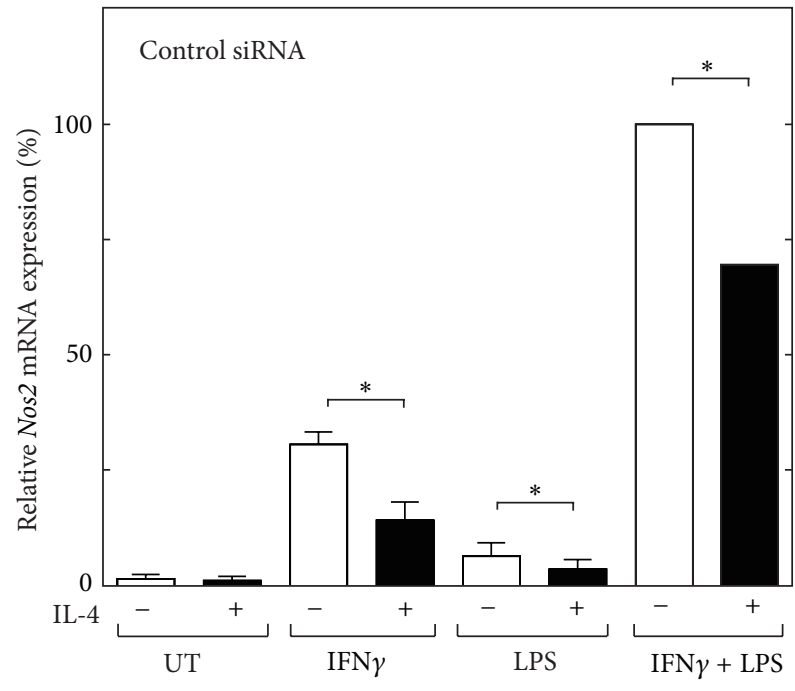

(c)

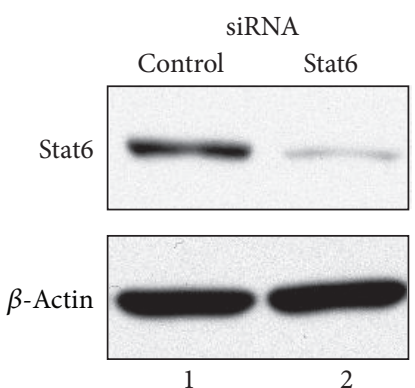

(b)

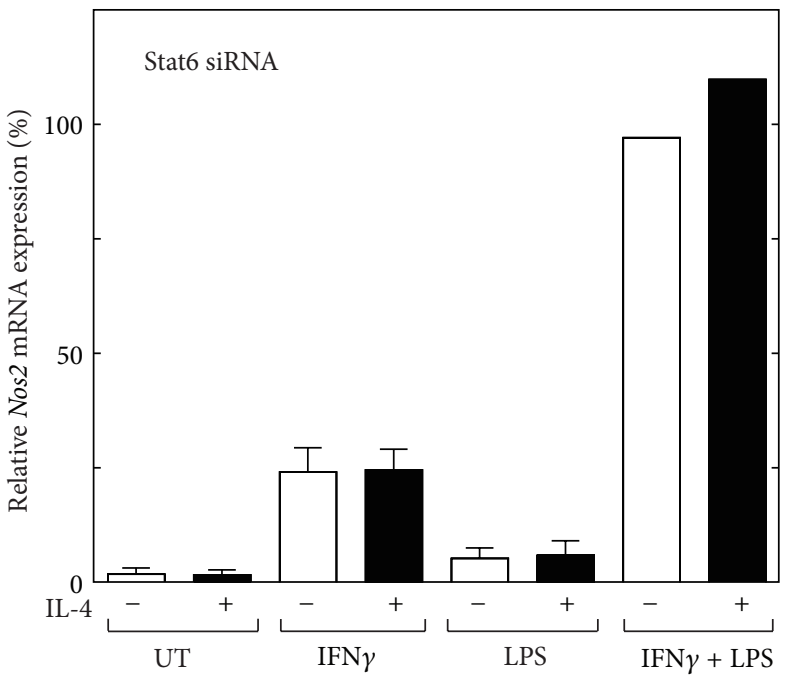

(d)

FIGURE 2: Stat6 is required for the IL-4-mediated inhibition of Nos2 gene expression in RAW264.7 cells. (a) RAW264.7 cells were transfected with control siRNA $(100 \mathrm{nM})$ or Stat6 siRNA $(100 \mathrm{nM})$ for 36 hours; total RNA was then prepared for quantitative real-time RT-PCR. Each column and bar represents the mean \pm SEM of three independent experiments. (b) RAW264.7 cells were transfected with siRNA, as described above, and then used to prepare total cellular lysates for a western blot analysis using an anti-Stat6 antibody. (c, d) RAW264.7 cells were transfected with control siRNA $(100 \mathrm{nM})$ or Stat6 siRNA $(100 \mathrm{nM})$. Thirty-six hours after transfection, the cells were either left untreated (UT) or treated with IL-4 (10 ng/mL) for 30 min prior to stimulation with IFN $\gamma(10 \mathrm{ng} / \mathrm{mL})$ and/or LPS (100 ng/mL) for $8 \mathrm{hours} \mathrm{before} \mathrm{the}$ preparation of total RNA for quantitative real-time RT-PCR. The relative Nos 2 mRNA expression levels are shown as percentages of the activity of cells transfected with the control siRNA and stimulated with IFN $\gamma$ and LPS. Each column and bar represents the mean \pm SEM of three independent experiments. The asterisks denote a statistically significant difference compared to the cultures treated with IL-4 $(P<0.05$, Student's $t$ test).

analyzed by northern hybridization (Figure 1). In agreement with previous studies $[12,28,34-36]$, pretreatment with IL-4 inhibited IFN $\gamma$ and/or LPS-induced Nos 2 mRNA expression.

The biological activity of IL-4 has been shown to be largely mediated by the transcription factor Stat6 $[16,17]$. Thus, to determine whether the inhibition of Nos2 gene expression by IL- 4 is mediated by Stat6, we knocked down Stat6 using a SMARTpool of siRNA targeting mouse Stat6. Real-time RT-PCR and western blotting analyses confirmed that siRNA-mediated Stat6 knockdown significantly decreased the levels of Stat 6 transcription and protein expression compared to the control siRNA treatment
(Figures 2(a) and 2(b)). In agreement with the decreased Stat6 level, the IL-4-mediated inhibition of Nos2 gene expression induced by IFN $\gamma$ and/or LPS was abolished in the cells transfected with Stat6 siRNA (Figure 2(d)). These results indicate that the IL-4-mediated inhibition of Nos2 gene expression depends on Stat6.

\subsection{Analysis of the Nos2 Regulatory Region for IL-4-Mediated} Inhibition. To examine the mechanism by which IL-4induced Stat6 inhibits Nos2 gene expression, we isolated the $5^{\prime}$-regulatory region of the mouse Nos 2 gene $(-996 \sim+104$ 


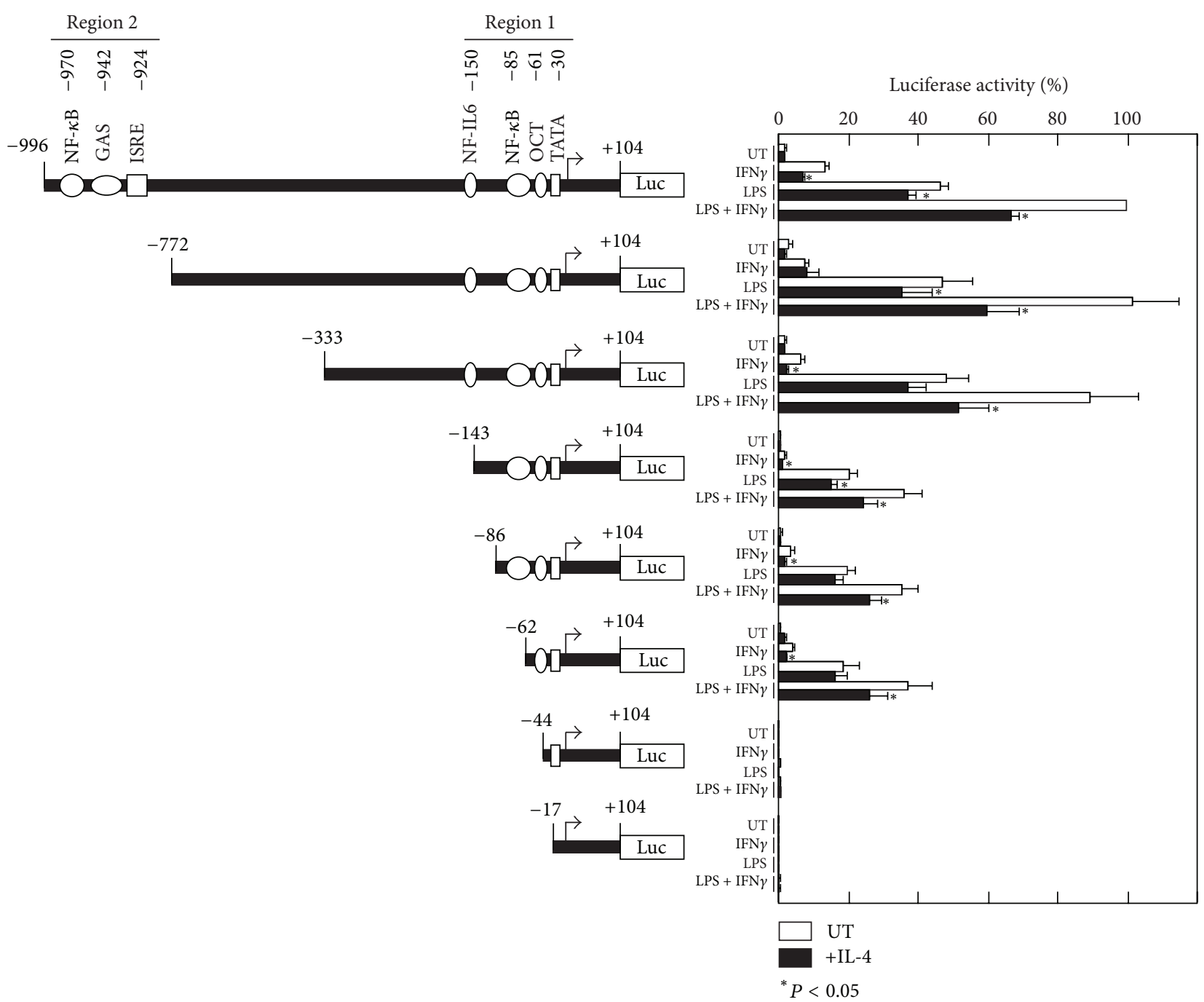

Figure 3: Deletion analysis of the mouse Nos2 enhancer/promoter region by luciferase reporter assays in RAW264.7 cells. The diagram on the left shows the wild-type (pNOS-996) and deletion constructs of the Nos2 luciferase reporter. The numbers above the enhancer/promoter region refer to the nucleotide positions relative to the transcriptional start site of the mouse Nos 2 gene. NF- $\kappa \mathrm{B}$, nuclear factor kappa B; GAS, gamma-IFN activation sequence; ISRE, interferon-stimulated responsive element; NF-IL-6, nuclear factor IL-6; OCT, octamer transcription factor; TATA, TATA-box. RAW264.7 cells were transiently transfected with wild-type or mutant Nos2 luciferase reporter constructs. Twentyfour hours after transfection, the cells were either left untreated (UT) or treated with IL-4 $(10 \mathrm{ng} / \mathrm{mL})$ for 30 min prior to stimulation with IFN $\gamma(10 \mathrm{ng} / \mathrm{mL})$ and/or LPS $(100 \mathrm{ng} / \mathrm{mL})$ for 8 hours before measurement of the luciferase activity. The relative luciferase activities are shown as percentages of the activity in cells transfected with the wild-type construct (pNOS-996) and stimulated with IFN $\gamma$ and LPS. Each column and bar represents the mean \pm SEM of five independent experiments. The asterisks denote a statistically significant difference compared to the cultures with IL-4 $(P<0.05$, Student's $t$ test $)$.

from the transcriptional start site) from mouse genomic DNA using PCR. We then cloned the amplified fragment into the pGL2 luciferase reporter plasmid (designated as pNOS-996) and analyzed the luciferase activity in a transient transfection assay in RAW264.7 cells (Figure 3). When the cells were stimulated with IFN $\gamma$ alone, a small but significant increase in luciferase activity was observed, whereas pre-treatment with IL- 4 inhibited this IFN $\gamma$-induced luciferase activity by $50 \%$. Stimulation with LPS alone strongly induced luciferase activity; IL-4 also inhibited the LPS-induced luciferase activity, though the magnitude of the inhibition was smaller than that of the IFN $\gamma$-induced luciferase activity. A synergistic induction of luciferase activity was observed when the cells were stimulated with a combination with IFN $\gamma$ and LPS, and pre-treatment with IL-4 also inhibited this luciferase activity.

To identify the regulatory region responsible for the IL-4-mediated inhibition of Nos2, a series of $5^{\prime}$ deletion mutants of the Nos 2 gene was analyzed. The deletion of the distal enhancer elements (region 2) diminished the IFN $\gamma$ induced luciferase activity (pNOS-772, pNOS-333); however, the LPS- and IFN $\gamma$ plus LPS-stimulated luciferase activities were comparable to the activity of the full-length promoter construct. Furthermore, pre-treatment with IL- 4 inhibited the luciferase activity induced by IFN $\gamma$ and LPS in cells 


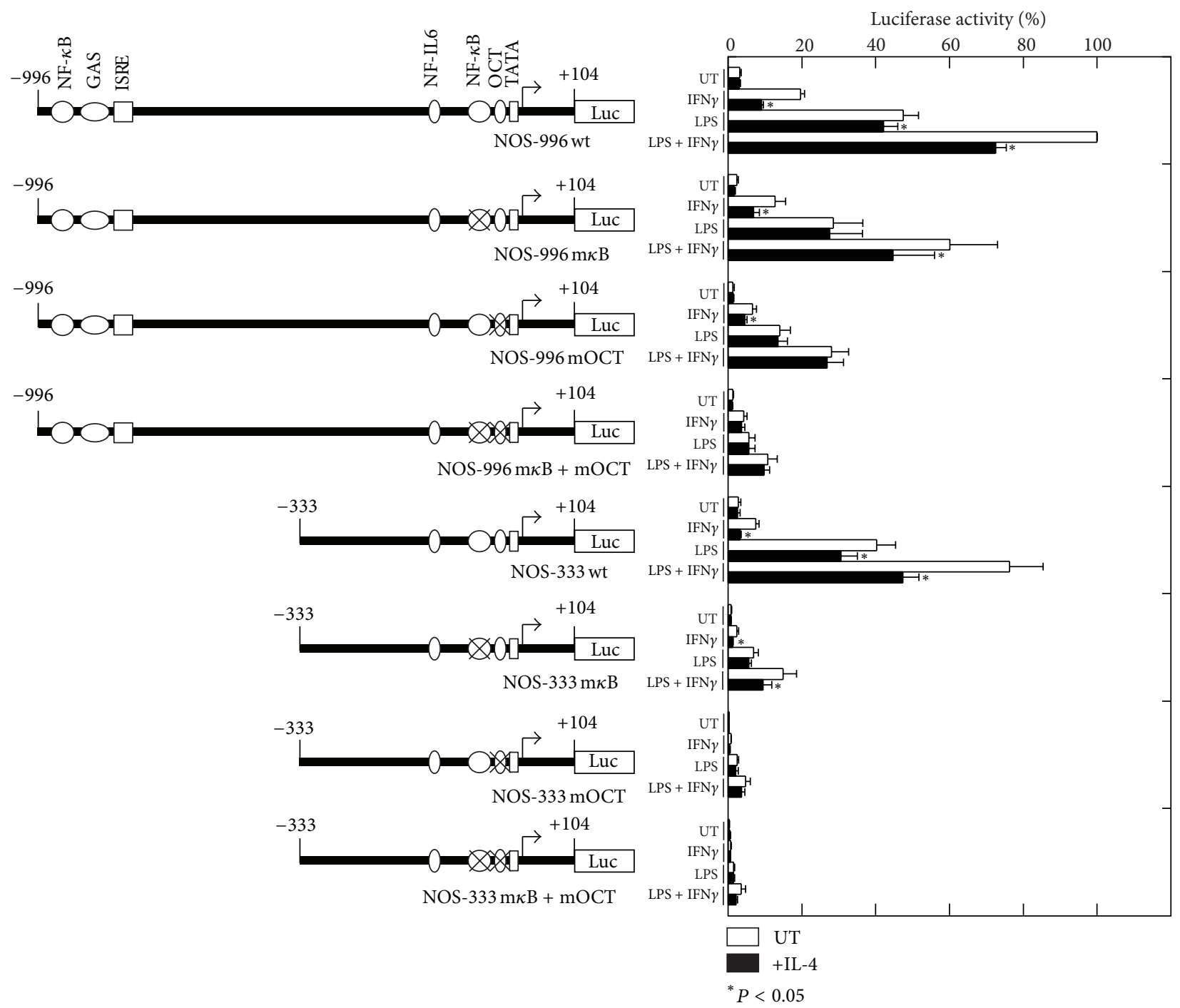

FIGURE 4: Mutational analysis of the mouse Nos2 enhancer/promoter region by luciferase reporter assays in RAW264.7 cells. The diagram on the left shows the wild-type (pNOS-996 and pNOS-333) and mutant Nos2 luciferase reporter constructs. Mutations of the NF- $\kappa$ B and/or OCT sites in the constructs are also indicated. RAW264.7 cells were transiently transfected with the wild-type or the mutant Nos2 luciferase reporter construct, as described above. The relative luciferase activities are shown as percentages of the activity in cells transfected with the wild-type construct (pNOS-996) and stimulated with IFN $\gamma$ and LPS. Each column and bar represents the mean \pm SEM of three independent experiments. The asterisks denote a statistically significant difference compared to the cultures treated with IL- 4 ( $P<0.05$, Student's $t$ test).

transfected with these reporter constructs. Deletion of the NF-IL-6 site (pNOS-143) diminished the constitutive activity and the IFN $\gamma$ and/or LPS-induced luciferase activity, indicating that this site contributes to the overall promoter activity; the IL-4-mediated inhibition of luciferase activity was still observed with this construct. Although the deletion of the NF- $\kappa$ B site (pNOS-62) only marginally affected the luciferase activity, deletion of the octamer (OCT) site almost completely abolished the activity (pNOS-44).

\subsection{The Octamer Transcription Factor Binding Site Is Involved} in the IL-4-Mediated Inhibition of Nos2 Gene Expression. Because the OCT site in the proximal promoter region appears to be critical for the transcriptional regulation of the
Nos 2 gene, site-specific mutations of this site, and the $\kappa \mathrm{B}$ sites were created in the full-length pNOS-996 luciferase construct and analyzed for their luciferase activity (Figure 4). Although mutation of the proximal $\kappa \mathrm{B}$ site diminished the LPS-induced luciferase activity and IL-4-mediated inhibition of luciferase activity, an inhibitory effect of IL- 4 on the IFN $\gamma$ - or IFN $\gamma$ plus LPS-induced luciferase activity was still observed. Nonetheless, mutation of the OCT site further diminished the IFN $\gamma$ and/or LPS-induced luciferase activity, and the inhibitory effect of IL-4 was also diminished, suggesting that the OCT site is responsible for mediating the inhibitory effect of IL-4. To determine the importance of the OCT site in the positive and negative regulation of the Nos 2 gene, the $\kappa \mathrm{B}$ and OCT sites were mutated within the context of pNOS-333 in which the distal enhancer region had been deleted. The mutation 
of $\kappa \mathrm{B}$ markedly reduced the LPS-induced luciferase activity, though the inhibitory effect of IL- 4 was still observed in the cells stimulated with IFN $\gamma$ - or IFN $\gamma$ plus LPS. When the OCT site was mutated, both the luciferase activity induced by IFN $\gamma$ and/or LPS and the inhibitory effect of IL-4 were markedly reduced. These results indicate that the OCT site appears to mediate the inhibitory effect of IL-4 in the transcriptional regulation of the Nos2 gene in RAW276.7 cells.

To further confirm the importance of the OCT site in the regulation of Nos2, this site was mutated by sitedirected mutagenesis within the context of the minimum promoter construct (pNOS-62), which contains the OCT site, a TATA box, and $104 \mathrm{bp}$ of the $5^{\prime}$-untranslated region; the ability of this construct to mediate the response to IFN $\gamma$ and/or LPS was then assessed in transient transfection assays (Figure 5). Mutation of the OCT site almost completely abolished the luciferase activity induced by IFN $\gamma$ and/or LPS, indicating that the OCT site is required for the transcriptional activation of the minimal promoter construct and that the transcriptional repression by IL- 4 is mediated through this site.

3.4. Analysis of OCT Binding Activity in Nuclear Extracts Prepared from RAW264.7 Cells. To examine whether IL-4 induces or modulates the nuclear factor(s) that specifically bind(s) to the OCT sequence, nuclear extracts were prepared from RAW264.7 cells and analyzed by EMSA using radiolabeled oligonucleotides corresponding to the OCT sequence (Figure 6). Constitutive DNA binding activity was observed in nuclear extracts from untreated cells, and this binding activity was not enhanced by either IFN $\gamma$ or LPS alone or in combination (Figure 6(a) lanes 1, 3, 5, and 7). In addition, these constitutive OCT-binding activities were not modified by IL- 4 treatment (lanes 2, 4, 6, and 8 ). A time-course experiment showed that no significant increase in the OCTbinding activity was observed in the nuclear extracts from RAW264.7 cells treated with IFN $\gamma$ and LPS (Figure 6(b)). The observed OCT-binding activity was specifically competed with a wild-type Nos2 OCT (wt NOS OCT) oligonucleotide (Figure 6(c), lane 2) and a consensus OCT motif from the immunoglobulin kappa chain (Igא) gene (wt Igא OCT) [46] (lane 4), whereas a mutant Nos2 OCT oligonucleotide (lane 3) did not compete in our EMSA. Although the OCT-binding activity was competed with the wild-type Nos2 OCT when the consensus Igk OCT motif was used as the probe (lane 6), the competition was less efficient compared to the Igא OCT motif (lane 8).

An antibody super-shift assay was then performed to identify the transcription factor that binds to the Nos2 OCT site (Figure 6(d)). An antibody against octamer transcription factor-1 (Oct-1) super-shifted the OCT-binding activity (lane 2 ), and an antibody against Oct- 2 diminished the band(s) migrating below the Oct-1 complex (lane 3). These results indicate that the OCT-binding complex mainly contains constitutively expressed Oct-1 and some Oct- 2 and that treatment with IL-4 had no effect on the binding of Oct proteins to the Nos2 OCT site. We also confirmed that IL-4

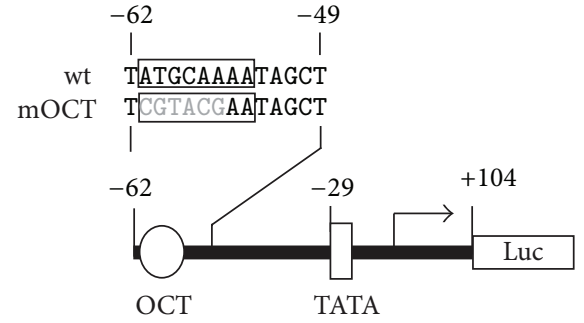

(a)

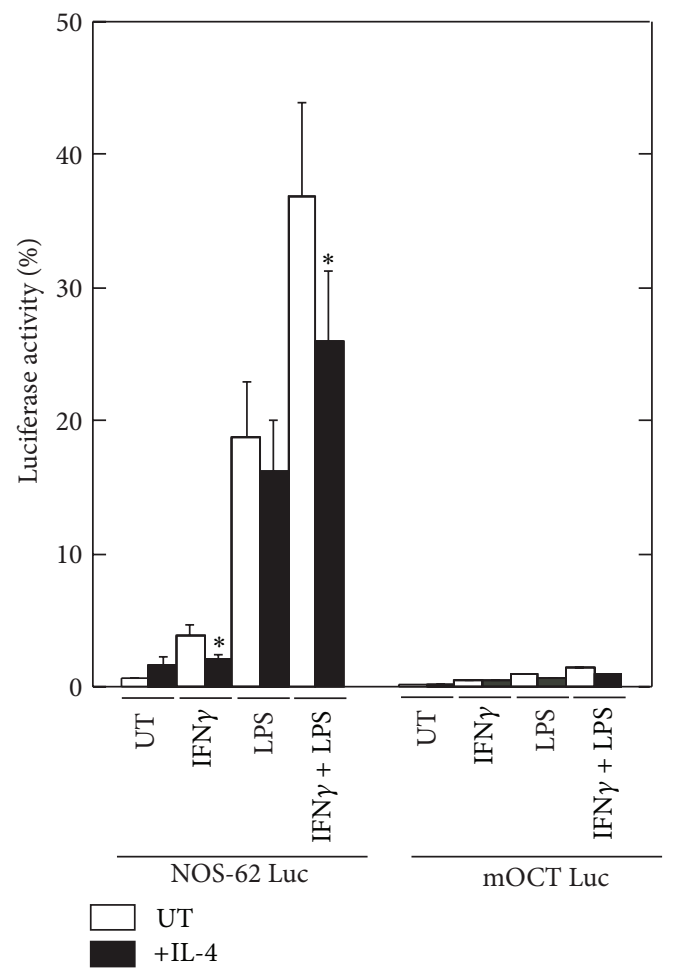

(b)

FIgURE 5: The OCT site in the Nos 2 promoter region is required for IFN $\gamma$ - and LPS-induced promoter activity. (a) The diagram shows the wild-type (wt) and mutant sequences of the OCT site (mOCT) in the Nos 2 minimum promoter region. The numbers above the promoter region refer to the nucleotide positions relative to the transcription start site of the mouse Nos2 gene. (b) RAW264.7 cells were transiently transfected with the NOS-62 luciferase reporter construct or a mutant construct containing a mutated OCT site (mOCT), as described above. The relative luciferase activities are shown as percentages of the activity in cells transfected with the wild-type construct (pNOS-996) and stimulated with IFN $\gamma$ and LPS. Each column and bar represents the mean \pm SEM of three independent experiments. The asterisks denote a statistically significant difference compared to the cultures treated with IL-4 $(P<0.05$, Student's $t$ test $)$.

had no inhibitory effect on Oct-1 or Oct-2 mRNA and protein expression in RAW 264.7 cells (supplemental Figure 2).

3.5. Overexpression of CBP Partially Attenuates the IL-4Mediated Inhibition of Nos2 Promoter Activity. Oct-1 and Oct-2 have been shown to interact with the coactivator 


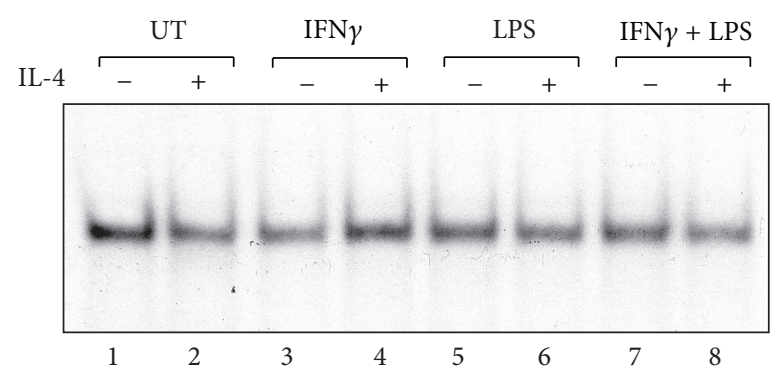

(a)

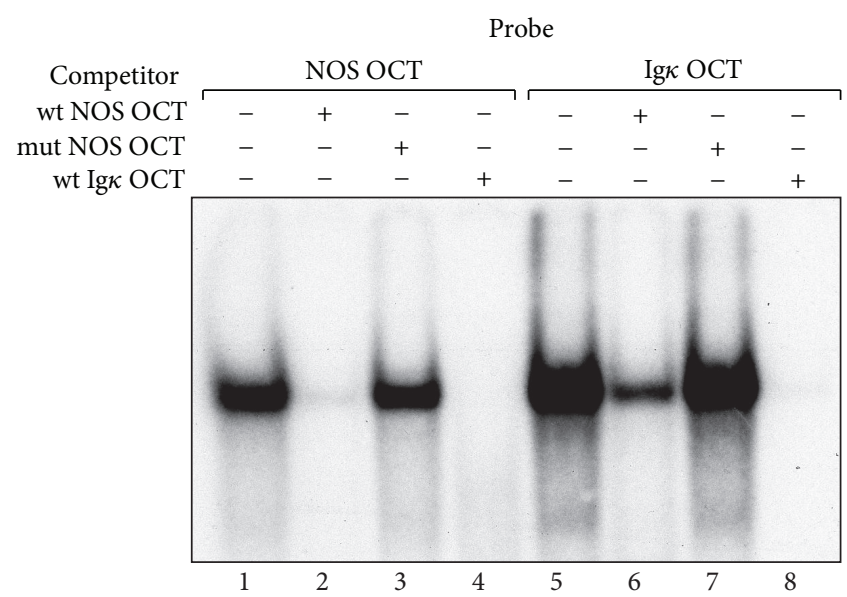

(c)

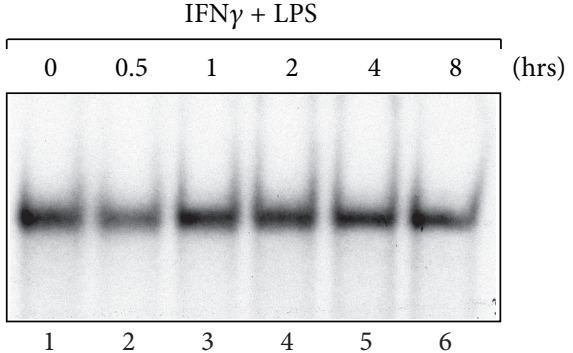

(b)

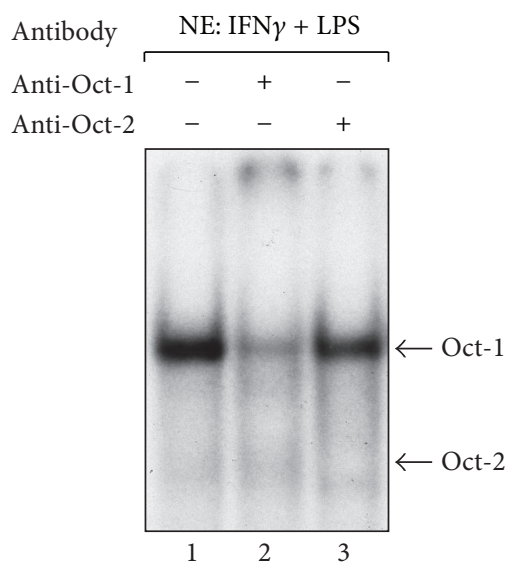

(d)

FIGURE 6: Analysis of OCT DNA-binding activity in nuclear extracts from RAW264.7 cells. (a) Effect of IL-4 treatment on OCT DNA-binding activity. RAW264.7 cells were treated with medium alone or IL-4 $(10 \mathrm{ng} / \mathrm{mL})$ for $30 \mathrm{~min}$ prior to stimulation with IFN $\gamma(10 \mathrm{ng} / \mathrm{mL})$ and/or LPS $(100 \mathrm{ng} / \mathrm{mL})$ for 4 hours before the preparation of nuclear extracts. The OCT binding activity was assessed by EMSA. (b) OCT DNAbinding activity in nuclear extracts from RAW264.7 cells treated with IFN $\gamma$ and LPS. RAW264.7 cells were cultured in the presence of IFN $\gamma$ $(10 \mathrm{ng} / \mathrm{mL})$ and LPS $(100 \mathrm{ng} / \mathrm{mL})$ for the indicated time prior to the preparation of nuclear extracts. In total, $10 \mu \mathrm{g}$ of each nuclear extract was analyzed for OCT binding activity by EMSA. (c) Analysis of OCT DNA-binding affinity to Nos2 OCT by an oligonucleotide competition assay. Nuclear extracts were prepared from RAW264.7 cells stimulated with IFN $\gamma(10 \mathrm{ng} / \mathrm{mL})$ and LPS (100 ng/mL) for $30 \mathrm{~min}$. The OCT DNA-binding activity was determined by EMSA using radio-labeled OCT oligonucleotides corresponding to the Nos2 OCT (NOS OCT) site or the immunoglobulin $\kappa$ chain OCT site (Igk OCT) in the presence or absence of a 25-fold excess of unlabeled wild-type (wt) or mutant (mut) oligonucleotide, as indicated. (d) Antibody super-shift assay for Nos2 OCT. Nuclear extracts (NE) from RAW264.7 cells stimulated with IFN $\gamma(10 \mathrm{ng} / \mathrm{mL})$ and LPS $(100 \mathrm{ng} / \mathrm{mL})$ for $30 \mathrm{~min}$ were incubated with the indicated antibodies $(1 \mu \mathrm{g}$ each) before analysis of the binding activity, as described above.

BOB.1/OBF.1 (official symbol: Pou2af1) and to promote OCTdependent transcription [47-49]. Because the Nos2 OCT binding activity was not modified by IL-4, a coactivator and/or cofactor that interacts with Oct-1 might be the target of IL-4-mediated inhibition. To examine the levels of endogenous BOB.1 protein in RAW264.7 cells, western blots were performed with lysates from cells stimulated with IFN $\gamma$ and/or LPS (Figure 7(a)). Although constitutive expression of the BOB.1 protein was observed in a mouse B cell line BCL1-B20 (lane 1), no detectable levels of BOB.1 protein were observed in the IFN $\gamma$ and/or LPS-stimulated RAW264.7 cells (lanes 2 5). These results suggest that a coactivator/cofactor other than BOB.1 is involved in the Oct1-dependent transcriptional activation and IL-4-mediated inhibition of the Nos 2 gene.

Because IL-4-induced Stat6 interacts with coactivator CREB-binding protein (CBP) in macrophages and CBP is expressed in mouse macrophages [19], we transfected a CBP expression vector into RAW264.7 cells and investigated the inhibitory effect of IL-4 on Nos 2 promoter activity. As shown in Figure 7(b), transfection with the CBP expression vector potentiated the IFN $\gamma$ - and LPS-induced Nos 2 promoter activity and partially attenuated the IL-4-mediated inhibition of promoter activity induced by IFN $\gamma$ and/or LPS. Taken together, these results suggest a model in which the IL-4mediated inhibition of Nos 2 promoter activity depends on a coactivator/cofactor that functionally promotes the Oct1-dependent transcriptional activation of the Nos 2 gene; furthermore, the transcriptional repression by IL- 4 might be mediated by the sequestration of this coactivator/cofactor by IL-4-induced Stat6.

\section{Discussion}

We and others have previously shown that Stat6 functions as a negative regulator of the anti-inflammatory activity of 


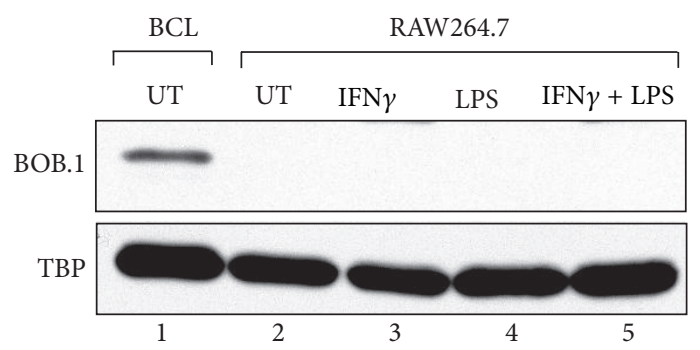

(a)
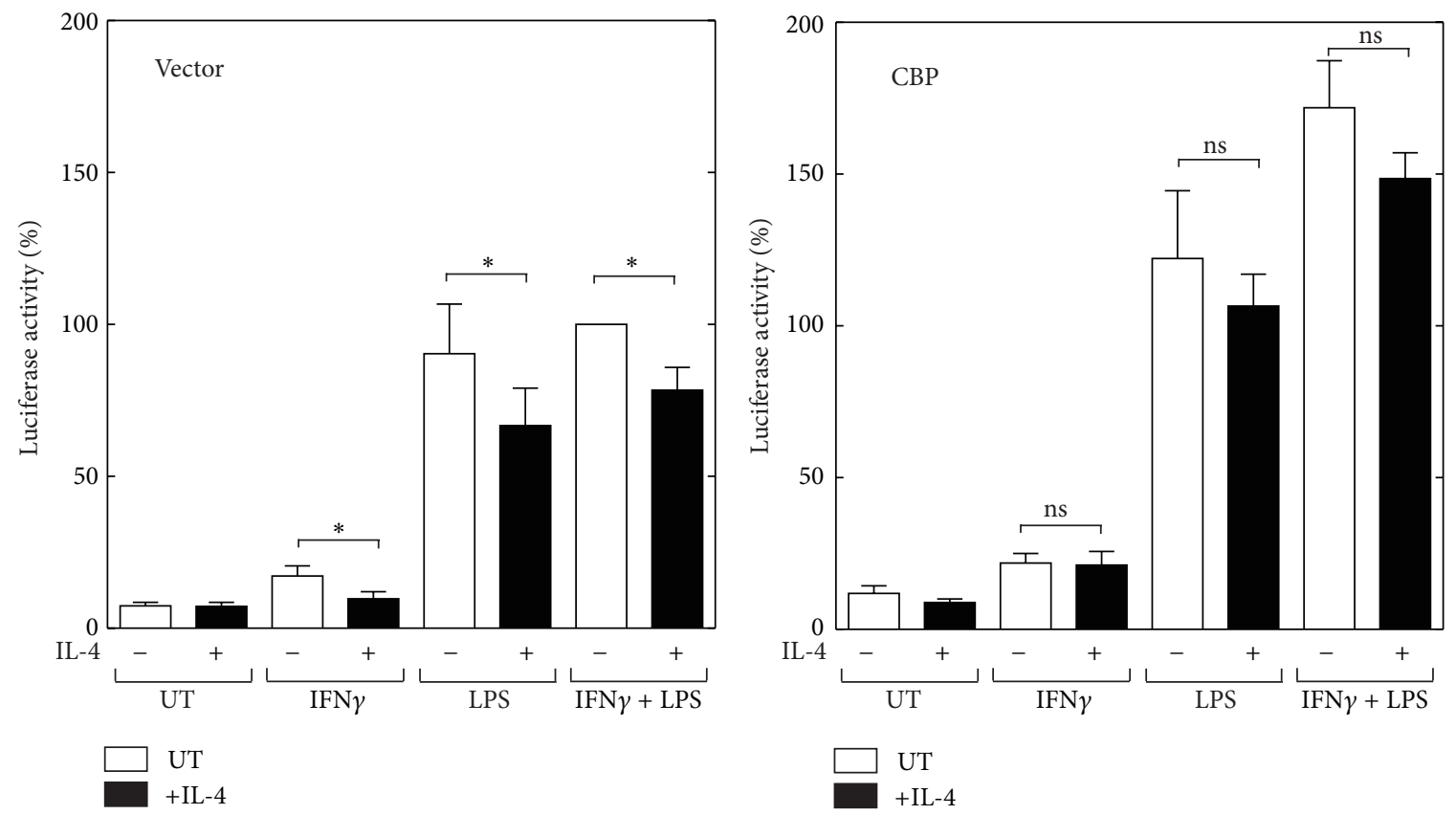

(b)

FIgURE 7: Overexpression of the coactivator CBP partially attenuates the IL-4-mediated inhibition of Nos2 promoter activity in RAW264.7 cells. (a) Analysis of endogenous BOB.1 expression in RAW264.7 cells. The cells were treated with medium alone (UT) or IFN $\gamma$ (10 ng/mL) and/or LPS (100 ng/mL) for 8 hours before the preparation of nuclear extracts. Twenty micrograms of nuclear extract was analyzed by western blotting using an antibody against BOB.1 or an antibody against TATA-binding protein (TBP), which was used as a loading control. Nuclear extracts from the mouse leukemia cell line BCL1-B20 (BCL) were used as a positive control for BOB.1 expression (lane 1). (b) RAW264.7 cells were transiently co-transfected with either the empty vector or wild-type CBP expression plasmid and the pNOS-62 luciferase reporter construct. Twenty-four hours after transfection, the cells were treated with medium alone (untreated: UT) or IL-4 (10 ng/mL) for $30 \mathrm{~min}$ prior to stimulation with IFN $\gamma(10 \mathrm{ng} / \mathrm{mL})$ and/or LPS $(100 \mathrm{ng} / \mathrm{mL})$ for 8 hours before the measurement of luciferase activity. The relative luciferase activities are shown as the percentage of the activity of cells transfected with the empty vector and stimulated with IFN $\gamma$ and LPS. Each column and bar represents the mean \pm SEM of three independent experiments. The asterisks denote a statistically significant difference compared to the cultures treated with IL-4 $(P<0.05$, Student's $t$ test; ns, not significant).

IL-4 or IL-13 in INF $\gamma$-induced macrophage gene expression $[19-21,50]$. Although Stat6 is required for the IL-4 or IL13 -mediated inhibition of mouse Nos 2 induced by IFN $\gamma$ and LPS in mouse macrophages [50], the molecular mechanisms involved in the Stat6-mediated inhibition remain to be fully elucidated. In the present study, we explored the mechanism involved in the IL-4-mediated inhibition of the Nos2 gene in the mouse macrophage-like cell line RAW264.7. We initially confirmed that Stat6 is necessary for the IL-4-mediated inhibition of Nos 2 gene expression using siRNA knockdown (Figure 2). We then investigated the mechanism by which IL-4-induced Stat6 inhibits the transcriptional activation of the Nos2 gene using a transient transfection assay with a luciferase reporter gene containing a series of $5^{\prime}$-deletion mutants and site-directed mutants of the Nos 2 regulatory region. Our results indicate that an OCT site located in the proximal promoter region of the Nos 2 gene is required for both the transcriptional activation induced by IFN $\gamma / \mathrm{LPS}$ and transcriptional repression by IL-4 in RAW264.7 cells. These conclusions are based on the following observations. Mutation of the OCT site within the context of the full-length Nos 2 promoter construct (pNOS-996 Luc) markedly reduced the promoter activity induced by INF $\gamma$ and/or LPS and the IL-4-mediated inhibition of promoter activity (Figure 4). 
A minimal promoter construct of the mouse Nos 2 gene (pNOS-62 Luc), which contains an OCT site and TATA box, retained the responsiveness to both IFN $\gamma / \mathrm{LPS}$ and IL4 , whereas mutation of the OCT site almost completely abolished this responsiveness (Figure 5).

The OCT site in the Nos 2 proximal promoter region has been shown to play a critical role in LPS-induced Nos 2 gene expression [31-33, 51-53]. The octamer motif (ATGCAAAT) is a conserved DNA binding element found in the promoter/enhancer region of many genes, including such ubiquitously expressed genes as the histone $\mathrm{H} 2 \mathrm{~B}$ gene, small nuclear RNA genes, and tissue-specific genes [54]. Members of the POU homeodomain family Oct-1 and Oct-2 recognize the OCT site of the mouse Nos 2 gene [32, 33, 51-53]. The results presented in this study are consistent with the previous observation that the octamer motif in the Nos 2 promoter is required for LPS-induced promoter activity. Furthermore, our findings demonstrate the essential role of this motif in IFN $\gamma$-induced promoter activity and the IL-4-mediated negative regulation of promoter activity. To our knowledge, this is the first demonstration that the OCT site in the Nos 2 promoter region mediates transcriptional repression by IL- 4 in mouse macrophages.

Previous research by Lu showed that LPS induces Oct2 expression in RAW264.7 cells and that trichostatin A, a histone deacetylase inhibitor, suppresses LPS-induced Nos2 expression by inhibiting LPS-induced Oct-2 expression [53], suggesting that Oct-2 activation is a crucial step for the transcriptional activation of the Nos 2 gene. Although we also observed an increase in Oct-2 mRNA and protein expression in RAW264.7 cells treated with LPS (supplemental Figure 2), IL-4 inhibition of the Nos 2 gene was not due to the downregulation of Oct-1 or Oct-2 expression: EMSA showed that, although octamer binding activities, which are mainly due to Oct-1 and a small amount of Oct-2, were observed in RAW264.7 cell nuclear extracts, IL-4 had no effect on the observed octamer biding activity (Figure 6). Furthermore, real-time RT-PCR and western blotting analyses showed that IL-4 had no inhibitory effect on the expression of the Oct-1 and Oct- 2 mRNAs and proteins (supplemental data). These lines of evidence indicate that the down-regulation of Oct1 and Oct-2 expression is not likely to be the mechanism by which IL-4 inhibits Nos 2 gene transcriptional activity.

The transcriptional activities of Oct-1 and Oct-2 are known to be enhanced by the lymphocyte-specific coactivator BOB.1/OBF.1 [47-49, 55]. Therefore, it is conceivable that a coactivator or cofactor that functionally interacts with Oct-1/Oct-2 might be a target for the IL-4-mediated transcriptional repression of Nos2, that is, IL-4-activated Stat 6 competes with a coactivator/cofactor that interacts with Oct-1. Thus, if the inhibition is mediated by competition for this coactivator/cofactor, overexpression of the coactivator/cofactor would attenuate the transcriptional repression by IL-4. However, BOB.1 has been shown to be a lymphocytespecific coactivator, and macrophage-lineage cells do not express BOB.1 $[48,56]$; we also confirmed that RAW264.7 cells did not express BOB.1, even upon stimulation with IFN $\gamma$ and/or LPS (Figure 7(a)). These findings suggest that a coactivator/cofactor other than BOB.1 that functionally interacts with Oct-1 or Oct- 2 may be a molecular target for the IL-4-mediated inhibition of the Nos 2 gene. We have previously shown that IL-4-induced Stat6 interacts with the coactivator CBP in macrophages; indeed, CBP is actually expressed in mouse macrophages [19]. Therefore, we tested the possibility that transfection with a CBP expression vector would affect the IL-4-mediated inhibition of Nos2 promoter activity. Transfection with a CBP expression vector partially attenuated the inhibitory effect of IL- 4 on IFN $\gamma / \mathrm{LPS}$ induced promoter activity, suggesting that CBP and another coactivator/cofactor that functionally interacts with Oct-1 may participate in the transcriptional repression. Oct-1 has been shown to interact with components of the general transcriptional machinery, including TBP, TFIIB, and TFIIH [57-60]. Further studies are required to examine whether IL4-activated STAT6 directly or indirectly interacts with these components and/or other coactivators/cofactors and inhibits the Oct-1-dependent transcriptional regulation of the Nos2 gene.

Nitric oxide produced by iNOS is a signature molecule involved in the classical activation of M1 macrophages. iNOS exerts antitumor and microbicidal activities against intracellular pathogens and functions as a potential hostdestructive mediator $[3,61]$. The functional competence of M1 macrophages, which is generally induced by such TLR ligands as LPS and the T-cell derived cytokine IFN $\gamma$, is negatively regulated by anti-inflammatory cytokines, including IL-4 and IL-13. Both cytokines, which are known to induce the alternative activation pathway in M2 macrophages, have been shown to regulate NO production by inducing arginase $I$, which catalyzes the hydrolysis of L-arginine, a common substrate of iNOS, and thereby down-regulates NO synthesis by competing with the substrate [8]. Because the induction of arginase I by IL-4/IL-13 is also regulated by Stat6 [62], IL4/IL-13-induced Stat6 appears to actively direct macrophages toward the M2 phenotype by inducing the expression of genes that are involved in the M2 phenotype, such as arginase $I$, and by inhibiting genes involved in the M1 phenotype, such as Nos2.

\section{Conclusions}

In conclusion, we demonstrate that the negative regulation of the mouse Nos 2 gene by IL- 4 in a mouse macrophage cell line depends on Stat6. Our analysis of the $5^{\prime}$-flanking regulatory region of the Nos 2 gene demonstrated that the OCT site in the proximal promoter region is required for negative regulation by IL-4. Our results suggest a model in which a coactivator/cofactor that functionally interacts with Oct- 1 is a molecular target for the IL-4-mediated inhibition of the Nos 2 gene and that IL-4-activated Stat6 represses Oct-1-dependent transcription by competing with this coactivator/cofactor.

\section{Conflict of Interests}

The authors declare that there is no conflict of interests. 


\section{Acknowledgments}

The authors thank Dr. Christopher K. Glass for providing the expression vectors. This work was supported by a grant-inaid for scientific research from the Ministry of Education, Science, and Culture of Japan.

\section{References}

[1] D. O. Adams and T. A. Hamilton, "The cell biology of macrophage activation," Annual Review of Immunology, vol. 2, pp. 283-318, 1984.

[2] J. B. Hibbs Jr., R. R. Taintor, H. A. Chapman Jr., and J. B. Weinberg, "Macrophage tumor killing: influence of the local environment," Science, vol. 197, no. 4300, pp. 279-282, 1977.

[3] S. Gordon, "Alternative activation of macrophages," Nature Reviews Immunology, vol. 3, no. 1, pp. 23-35, 2003.

[4] Q. Xie, H. J. Cho, J. Calaycay et al., "Cloning and characterization of inducible nitric oxide synthase from mouse macrophages," Science, vol. 256, no. 5054, pp. 225-228, 1992.

[5] R. B. Lorsbach, W. J. Murphy, C. J. Lowenstein, S. H. Snyder, and S. W. Russell, "Expression of the nitric oxide synthase gene in mouse macrophages activated for tumor cell killing. Molecular basis for the synergy between interferon- $\gamma$ and lipopolysaccharide," The Journal of Biological Chemistry, vol. 268, no. 3, pp. 1908-1913, 1993.

[6] M. Stein, S. Keshav, N. Harris, and S. Gordon, "Interleukin 4 potently enhances murine macrophage mannose receptor activity: a marker of alternative immunologic macrophage activation," Journal of Experimental Medicine, vol. 176, no. 1, pp. 287-292, 1992.

[7] Y. Ohmori, M. F. Smith Jr., and T. A. Hamilton, "IL-4-induced expression of the IL-1 receptor antagonist gene Is mediated by STAT6," The Journal of Immunology, vol. 157, no. 5, pp. 20582065, 1996.

[8] M. Munder, K. Eichmann, J. M. Morán, F. Centeno, G. Soler, and M. Modolell, "Th1/Th2-regulated expression of arginase isoforms in murine macrophages and dendritic cells," The Journal of Immunology, vol. 163, no. 7, pp. 3771-3777, 1999.

[9] R. Essner, K. Rhoades, W. H. McBride, D. L. Morton, and J. S. Economou, "IL-4 down-regulates IL-1 and TNF gene expression in human monocytes," The Journal of Immunology, vol. 142, no. 11, pp. 3857-3861, 1989.

[10] M. J. Fenton, J. A. Buras, and R. P. Donnelly, "IL-4 reciprocally regulates IL-1 and IL-1 receptor antagonist expression in human monocytes," The Journal of Immunology, vol. 149, no. 4, pp. 12831288, 1992.

[11] W. Deng, Y. Ohmori, and T. A. Hamilton, "Mechanisms of IL4-mediated suppression of IP-10 gene expression in murine macrophages," The Journal of Immunology, vol. 153, no. 5, pp. 2130-2136, 1994.

[12] C. Bogdan, Y. Vodovotz, J. Paik, Q. Xie, and C. Nathan, "Mechanism of suppression of nitric oxide synthase expression by interleukin-4 in primary mouse macrophages," Journal of Leukocyte Biology, vol. 55, no. 2, pp. 227-233, 1994.

[13] H. Kotanides and N. C. Reich, "Requirement of tyrosine phosphorylation for rapid activation of a DNA binding factor by IL-4," Science, vol. 262, no. 5137, pp. 1265-1267, 1993.

[14] J. Hou, U. Schindler, W. J. Henzel, T. C. Ho, M. Brasseur, and S. L. McKnight, "An interleukin-4-induced transcription factor: IL-4 Stat," Science, vol. 265, no. 5179, pp. 1701-1706, 1994.
[15] C. Schindler, H. Kashleva, A. Pernis, R. Pine, and P. Rothman, "STF-IL-4: a novel IL-4-induced signal transducing factor," The EMBO Journal, vol. 13, no. 6, pp. 1350-1356, 1994.

[16] M. H. Kaplan, U. Schindler, S. T. Smiley, and M. J. Grusby, "Stat6 is required for mediating responses to IL- 4 and for the development of Th2 cells," Immunity, vol. 4, no. 3, pp. 313-319, 1996.

[17] K. Takeda, T. Tanaka, W. Shi et al., "Essential role of Stat6 in IL-4 signalling," Nature, vol. 380, no. 6575, pp. 627-630, 1996.

[18] K. Nelms, A. D. Keegan, J. Zamorano, J. J. Ryan, and W. E. Paul, "The IL-4 receptor: signaling mechanisms and biologic functions," Annual Review of Immunology, vol. 17, pp. 701-738, 1999.

[19] Y. Ohmori and T. A. Hamilton, "STAT6 is required for the anti-inflammatory activity of interleukin- 4 in mouse peritoneal macrophages," The Journal of Biological Chemistry, vol. 273, no. 44, pp. 29202-29209, 1998.

[20] S. Goenka, J. Youn, L. M. Dzurek, U. Schindler, L.-Y. Yu-Lee, and M. Boothby, "Paired Stat6 C-terminal transcription activation domains required both for inhibition of an IFN-responsive promoter and trans-activation," The Journal of Immunology, vol. 163, no. 9, pp. 4663-4672, 1999.

[21] V. T. Nguyen and E. N. Benveniste, "IL-4-activated STAT6 inhibits IFN- $\gamma$-induced $\mathrm{CD} 40$ gene expression in macrophages/microglia," The Journal of Immunology, vol. 165 , no. 11, pp. 6235-6243, 2000.

[22] Y. Ohmori and T. A. Hamilton, "Interleukin-4/STAT6 represses STAT1 and NF- $\kappa$ B-dependent transcription through distinct mechanisms," The Journal of Biological Chemistry, vol. 275, no. 48, pp. 38095-38103, 2000.

[23] C. J. Lowenstein, E. W. Alley, P. Raval et al., "Macrophage nitric oxide synthase gene: two upstream regions mediate induction by interferon $\gamma$ and lipopolysaccharide," Proceedings of the National Academy of Sciences of the United States of America, vol. 90, no. 20, pp. 9730-9734, 1993.

[24] Q.-W. Xie, R. Whisnant, and C. Nathan, "Promoter of the mouse gene encoding calcium-independent nitric oxide synthase confers inducibility by interferon $\gamma$ and bacterial lipopolysaccharide," Journal of Experimental Medicine, vol. 177, no. 6, pp. 17791784, 1993.

[25] R. Kamijo, H. Harada, T. Matsuyama et al., "Requirement for transcription factor IRF-1 in NO synthase induction in macrophages," Science, vol. 263, no. 5153, pp. 1612-1615, 1994.

[26] E. Martin, C. Nathan, and Q.-W. Xie, "Role of interferon regulatory factor 1 in induction of nitric oxide synthase," Journal of Experimental Medicine, vol. 180, no. 3, pp. 977-984, 1994.

[27] J. Gao, D. C. Morrison, T. J. Parmely, S. W. Russell, and W. J. Murphy, "An interferon- $\gamma$-activated site (GAS) is necessary for full expression of the mouse iNOS gene in response to interferon- $\gamma$ and lipopolysaccharide," The Journal of Biological Chemistry, vol. 272, no. 2, pp. 1226-1230, 1997.

[28] H. Xiong, C. Zhu, H. Li et al., "Complex formation of the interferon (IFN) consensus sequence-binding protein with IRF1 is essential for murine macrophage IFN- $\gamma$-induced iNOS gene expression," The Journal of Biological Chemistry, vol. 278, no. 4, pp. 2271-2277, 2003.

[29] W.-G. Deng and K. K. Wu, "Regulation of inducible nitric oxide synthase expression by p 300 and p50 acetylation," The Journal of Immunology, vol. 171, no. 12, pp. 6581-6588, 2003.

[30] M. Farlik, B. Reutterer, C. Schindler et al., "Nonconventional initiation complex assembly by STAT and NF- $\kappa$ B transcription 
factors regulates nitric oxide synthase expression," Immunity, vol. 33, no. 1, pp. 25-34, 2010.

[31] C. E. P. Goldring, S. Reveneau, M. Algarté, and J.-F. Jeannin, "In vivo footprinting of the mouse inducible nitric oxide synthase gene: inducible protein occupation of numerous sites including Oct and NF-IL6," Nucleic Acids Research, vol. 24, no. 9, pp. 16821687, 1996.

[32] Q.-W. Xie, "A novel lipopolysaccharide-response element contributes to induction of nitric oxide synthase," The Journal of Biological Chemistry, vol. 272, no. 23, pp. 14867-14872, 1997.

[33] Y.-M. Kim, C.-B. Ko, Y.-P. Park, Y. J. Kim, and S.-G. Paik, "Octamer motif is required for the NF- $\kappa \mathrm{B}$-mediated induction of the inducible nitric oxide synthase gene expression in RAW 264.7 macrophages," Molecules and Cells, vol. 9, no. 1, pp. 99109, 1999.

[34] E. M. Coccia, E. Stellacci, G. Marziali, G. Weiss, and A. Battistini, "IFN- $\gamma$ and IL-4 differently regulate inducible NO synthase gene expression through IRF-1 modulation," International Immunology, vol. 12, no. 7, pp. 977-985, 2000.

[35] K. R. Morris, R. D. Lutz, X. Bai et al., "Suppression of IFN $\gamma+$ mycobacterial lipoarabinomannan-induced NO by IL- 4 is due to decreased IRF-1 expression," Tuberculosis, vol. 89, no. 4, pp. 294-303, 2009.

[36] S. R. Paludan, S. Ellermann-Eriksen, J. Lovmand, and S. C. Mogensen, "Interleukin-4-mediated inhibition of nitric oxide production in interferon- $\gamma$-treated and virus-infected macrophages," Scandinavian Journal of Immunology, vol. 49, no. 2, pp. 169-176, 1999.

[37] S. Mita, N. Harada, S. Naomi et al., "Receptors for T cellreplacing factor/interleukin 5. Specificity, quantitation, and its implication," Journal of Experimental Medicine, vol. 168, no. 3, pp. 863-878, 1988.

[38] A. H. Ding, C. F. Nathan, and D. J. Stuehr, "Release of reactive nitrogen intermediates and reactive oxygen intermediates from mouse peritoneal macrophages: comparison of activating cytokines and evidence for independent production," The Journal of Immunology, vol. 141, no. 7, pp. 2407-2412, 1988.

[39] M. M. Bradford, "A rapid and sensitive method for the quantitation of microgram quantities of protein utilizing the principle of protein dye binding," Analytical Biochemistry, vol. 72, no. 1-2, pp. 248-254, 1976.

[40] Y. Ohmori and T. A. Hamilton, "IFN- $\gamma$ selectively inhibits lipopolysaccharide-inducible JE/monocyte chemoattractant protein-1 and $\mathrm{KC} / \mathrm{GRO} /$ melanoma growth-stimulating activity gene expression in mouse peritoneal macrophages," The Journal of Immunology, vol. 153, no. 5, pp. 2204-2212, 1994.

[41] W. Deng, B. Thiel, C. S. Tannenbaum, T. A. Hamilton, and D. J. Stuehr, "Synergistic cooperation between T cell lymphokines for induction of the nitric oxide synthase gene in murine peritoneal macrophages," The Journal of Immunology, vol. 151, no. 1, pp. 322-329, 1993.

[42] J. Sambrook and D. W. Russell, "Mutagenesis," in Molecular Cloning: A Laboratory Manual, J. Sambrook and D. W. Russell, Eds., pp. 13.11-13.39, Cold Spring Harbor, 2001.

[43] Y. Kamei, L. Xu, T. Heinzel et al., "A CBP integrator complex mediates transcriptional activation and AP-1 inhibition by nuclear receptors," Cell, vol. 85, no. 3, pp. 403-414, 1996.

[44] J. D. Dignani, R. M. Lebovitz, and R. G. Roeder, "Accurate transcription initiation by RNA polymerase II in a soluble extract from isolated mammalian nuclei," Nucleic Acids Research, vol. 11, no. 5, pp. 1475-1489, 1983.
[45] Y. Ohmori and T. A. Hamilton, "The interferon-stimulated response element and a $\kappa \mathrm{B}$ site mediate synergistic induction of murine IP-10 gene transcription by IFN- $\gamma$ and TNF- $\alpha$," The Journal of Immunology, vol. 154, no. 10, pp. 5235-5244, 1995.

[46] F. G. Falkner and H. G. Zachau, "Correct transcription of an immunoglobulin $\kappa$ gene requires an upstream fragment containing conserved sequence elements," Nature, vol. 310, no. 5972, pp. 71-74, 1984.

[47] M. Gstaiger, L. Knoepfel, O. Georgiev, W. Schaffner, and C. M. Hovens, "A B-cell coactivator of octamer-binding transcription factors," Nature, vol. 373, no. 6512, pp. 360-362, 1995.

[48] M. Strubin, J. W. Newell, and P. Matthias, "OBF-1, a novel B cellspecific coactivator that stimulates immunoglobulin promoter activity through association with octamer-binding proteins," Cell, vol. 80, no. 3, pp. 497-506, 1995.

[49] P. Pfisterer, S. Zwilling, J. Hess, and T. Wirth, "Functional characterization of the murine homolog of the $\mathrm{B}$ cell-specific coactivator BOB.1/OBF.1," The Journal of Biological Chemistry, vol. 270, no. 50, pp. 29870-29880, 1995.

[50] K. Takeda, M. Kamanaka, T. Tanaka, T. Kishimoto, and S. Akira, "Impaired IL-13-mediated functions of macrophages in STAT6deficient mice," The Journal of Immunology, vol. 157, no. 8, pp. 3220-3222, 1996.

[51] T. Sawada, L. A. Falk, P. Rao, W. J. Murphy, and D. H. Pluznik, "IL-6 induction of protein-DNA complexes via a novel regulatory region of the inducible nitric oxide synthase gene promoter: role of octamer binding proteins," The Journal of Immunology, vol. 158, no. 11, pp. 5267-5276, 1997.

[52] B.-S. Lee, Y.-M. Kim, H.-S. Kang, H. M. K. Hwan Mook Kim, K.H. Pyun, and I. Choi, "Octamer binding protein-1 is involved in inhibition of inducible nitric oxide synthase expression by exogenous nitric oxide in murine liver cells," Journal of Biochemistry, vol. 129, no. 1, pp. 77-86, 2001.

[53] S.-C. Lu, H.-W. Wu, Y.-J. Lin, and S.-F. Chang, "The essential role of Oct-2 in LPS-induced expression of iNOS in RAW 264.7 macrophages and its regulation by trichostatin A," The American Journal of Physiology-Cell Physiology, vol. 296, no. 5, pp. C1133-C1139, 2009.

[54] W. Herr and M. A. Cleary, "The POU domain: versatility in transcriptional regulation by a flexible two-in-one DNAbinding domain," Genes and Development, vol. 9, no. 14, pp. 1679-1693, 1995.

[55] H. Laumen, P. J. Nielsen, and T. Wirth, "The BOB.1/OBF.1 coactivator is essential for octamer-dependent transcription in $\mathrm{B}$ cells," European Journal of Immunology, vol. 30, no. 2, pp. 458469, 2000.

[56] B. Kistler, P. Pfisterer, and T. Wirth, "Lymphoid- and myeloidspecific activity of the PU.1 promoter is determined by the combinatorial action of octamer and ets transcription factors," Oncogene, vol. 11, no. 6, pp. 1095-1106, 1995.

[57] S. Zwilling, A. Annweiler, and T. Wirth, "The POU domains of the Oct1 and Oct2 transcription factors mediate specific interaction with TBP," Nucleic Acids Research, vol. 22, no. 9, pp. 1655-1662, 1994.

[58] H. Nakshatri, P. Nakshatri, and R. A. Currie, "Interaction of Oct-1 with TFIIB. Implications for a novel response elicited through the proximal octamer site of the lipoprotein lipase promoter," The Journal of Biological Chemistry, vol. 270, no. 33, pp. 19613-19623, 1995.

[59] S. Inamotc, N. Segil, Z.-Q. Pan, M. Kimura, and R. G. Roeder, "The cyclin-dependent kinase-activating kinase (CAK) assembly factor, MAT1, targets and enhances CAK activity on the 
POU domains of octamer transcription factors," The Journal of Biological Chemistry, vol. 272, no. 47, pp. 29852-29858, 1997.

[60] E. Bertolino and H. Singh, "POU/TBP cooperativity: a mechanism for enhancer action from a distance," Molecular Cell, vol. 10, no. 2, pp. 397-407, 2002.

[61] C. Nathan, "Nitric oxide as a secretory product of mammalian cells," The FASEB Journal, vol. 6, no. 12, pp. 3051-3064, 1992.

[62] R. Rutschman, R. Lang, M. Hesse, J. N. Ihle, T. A. Wynn, and P. J. Murray, "Cutting edge: Stat6-dependent substrate depletion regulates nitric oxide production," The Journal of Immunology, vol. 166, no. 4, pp. 2173-2177, 2001. 


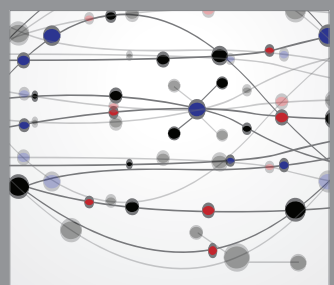

The Scientific World Journal
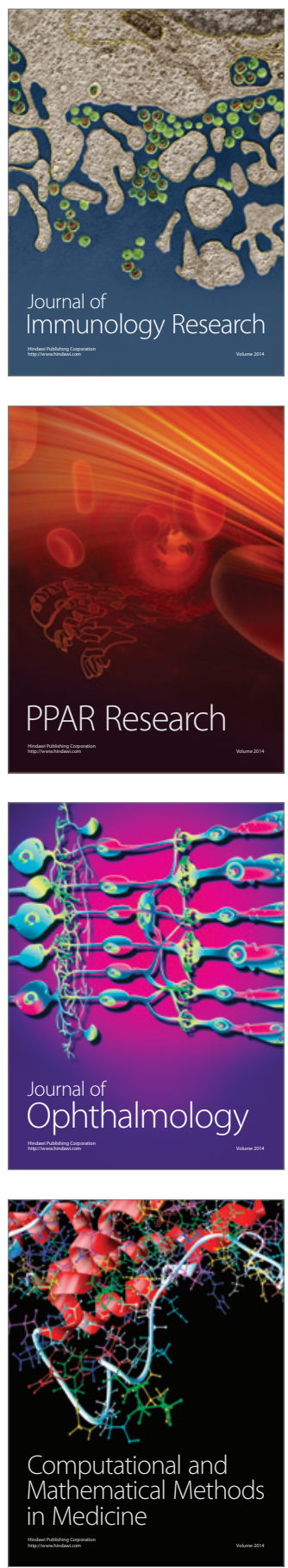

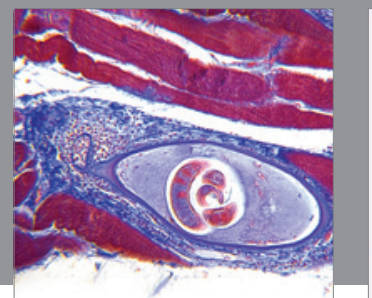

Gastroenterology

Research and Practice
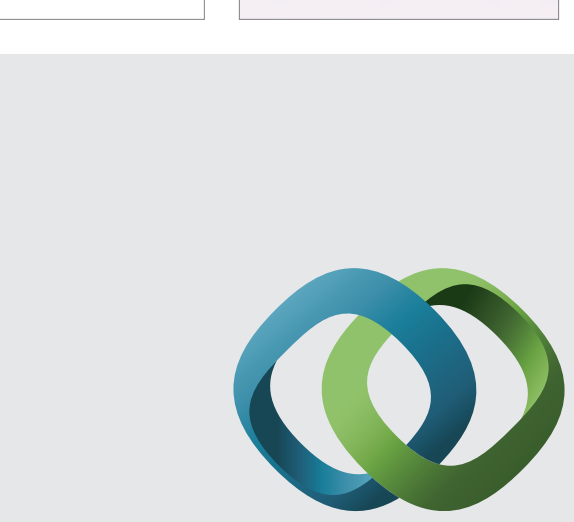

\section{Hindawi}

Submit your manuscripts at

http://www.hindawi.com
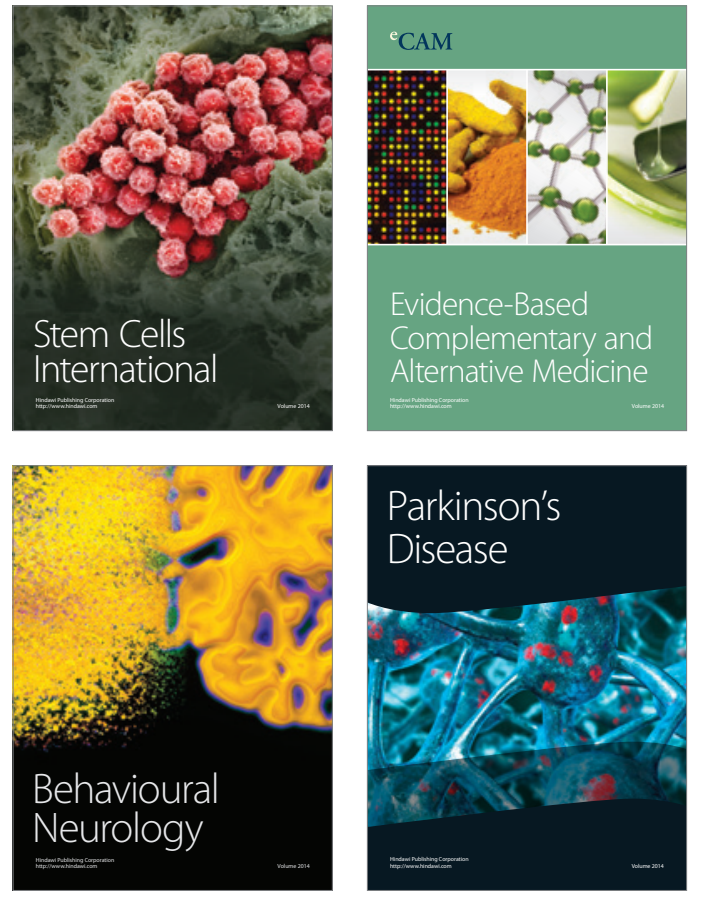
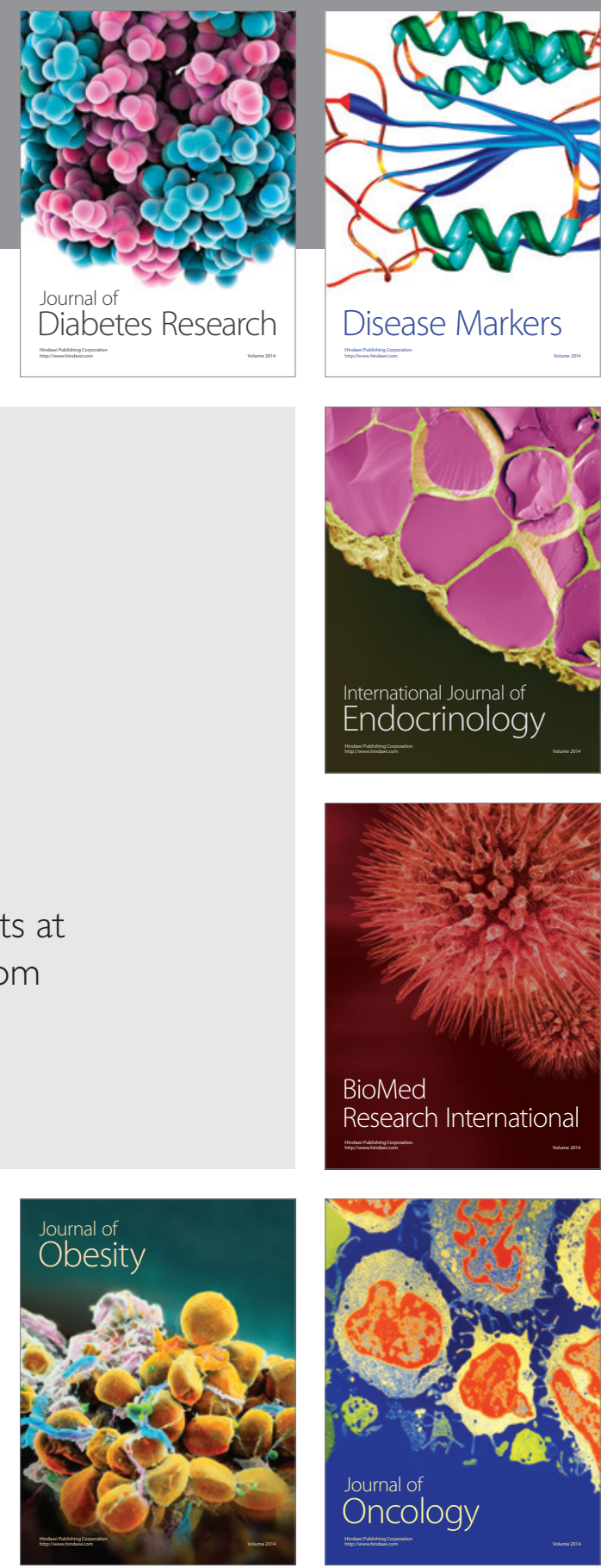

Disease Markers
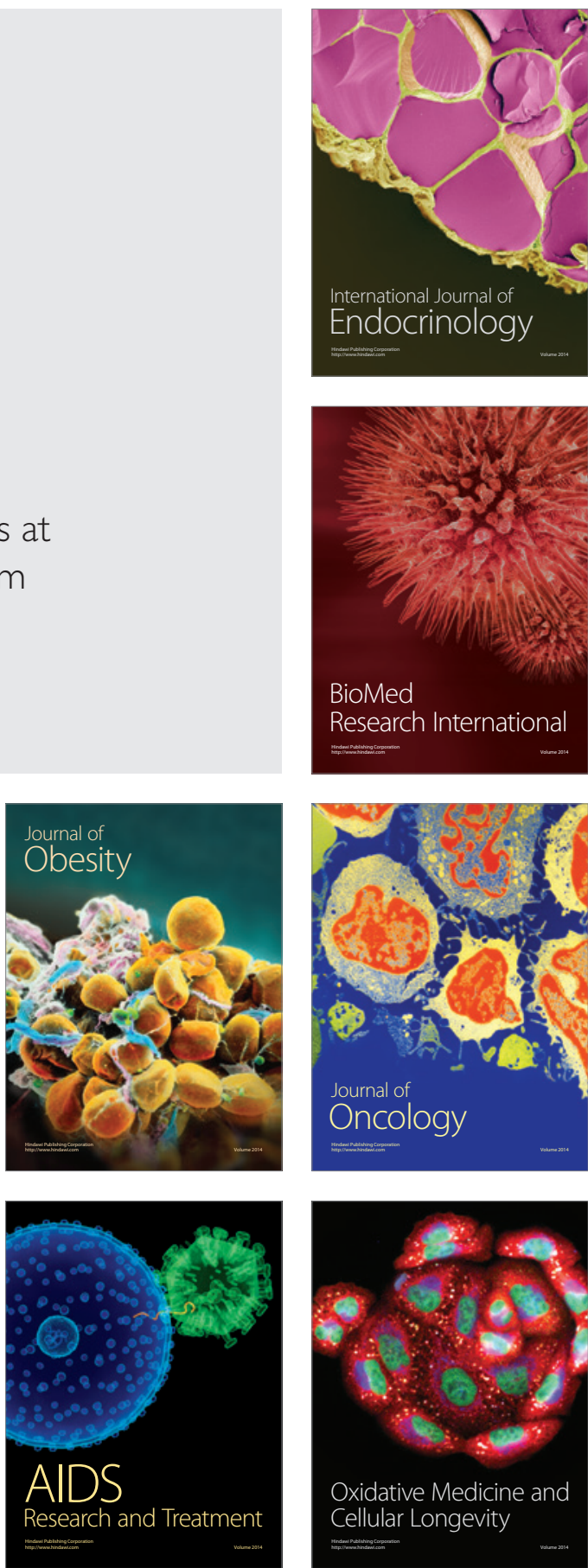